See discussions, stats, and author profiles for this publication at: https://www.researchgate.net/publication/346088238

\title{
Is Additive Manufacturing Improving Performance in Sports? A Systematic
} Review

Article in Proceedings of the Institution of Mechanical Engineers Part P Journal of Sports Engineering and Technology · November 2020 DOI: 10.1177/1754337120971521

CITATIONS

2 authors:

2.

James I. Novak

Deakin University

34 PUBLICATIONS 110 CITATIONS

SEE PROFILE

Some of the authors of this publication are also working on these related projects:

Project Implicit precueing affects motor behaviour View project

Project Additive Manufacturing Health Applications View project

\section{READS}

17

Andrew Novak

University of Technology Sydney / Rugby Australia

35 PUBLICATIONS 152 CITATIONS

SEE PROFILE 


\title{
Is Additive Manufacturing Improving Performance in Sports? A Systematic Review
}

\author{
James I. Novak ${ }^{\mathrm{a}}$, Andrew R. Novak ${ }^{\mathrm{b}, \mathrm{c}}$
}

a. School of Engineering, Deakin University, Australia

b. Human Performance Research Centre, Sport and Exercise Science, Faculty of Health, University of Technology Sydney, Moore Park, Australia.

c. High Performance Department, Rugby Australia, Moore Park, Australia.

\section{Corresponding Author:}

James I. Novak

School of Engineering

Faculty of Science, Engineering and Built Environment

Locked Bag 20000

Geelong, VIC 3220

Australia

Email: james.novak@deakin.edu.au

\begin{abstract}
Sport is an industry that may benefit from the opportunities offered by Additive Manufacturing (AM), and the media has portrayed increasing adoption of the technology in sports products. This systematic review aimed to consolidate and interpret the available empirical evidence concerning applications of AM in sports following the Preferred Reporting Items for Systematic Review and Meta-Analysis Protocols (PRISMA-P) 2015. Four databases were searched within the date range of January 1984 to May 2019, using twenty-eight broad and specific search phrases. This resulted in twenty-six articles for analysis, the first appearing in 2010. Twelve sports in total were identified across the literature, with running/walking the most popular sport with ten articles (38\%) investigating AM, followed by cycling with four articles (15\%) and badminton with three articles (12\%). Ten articles (38\%) observed improvements in performance of products developed via AM compared to conventionally manufactured products, eight articles (31\%) found a similar performance, and five articles $(19 \%)$ found a lower performance. From a technical perspective, powder bed fusion technologies were the most utilized with $50 \%$ of articles using either selective laser sintering (SLS) or selective laser melting (SLM), although $52 \%$ of articles did not name the 3D printer used and $36 \%$ did not name any software used to design or optimize products. 3D scanning technology was also utilized within eleven (42\%) articles. Results indicate that AM has been slow to permeate sports research, and while considered across a variety of potential applications, has largely resulted in singular studies with potentially limited opportunities or funding for follow-up investigations.
\end{abstract}

Keywords: 3D printing, 3D scanning, literature review, performance, PRISMA-P, product design, sport technology 


\section{Introduction}

Additive manufacturing (AM), synonymously known as three-dimensional (3D) printing, ${ }^{1}$ has emerged over the last decade as a transformative technology across many manufacturing sectors, from advanced aerospace and medical applications through to more personalized applications in fashion and product design. This industry is estimated to be worth US $\$ 15.8$ billion in 2020, forecast to more than double to US $\$ 35.6$ billion in $2024 .^{2}$ The transition from a rapid prototyping technology to one capable of producing functional end-use parts has seen AM become mainstream within some industries. ${ }^{3-5}$ For example, the production of in-ear hearing aids largely shifted to additive processes between 2000-2006 for all major manufacturers, ${ }^{6}$ more than 60,000 acetabular cups fabricated using electron beam melting were implanted in patients by $2017,{ }^{7}$ and GE Additive and Boeing currently manufacture tens of thousands of aircraft components annually using both polymer and metal 3D printing. ${ }^{8}$ Industries like transport (e.g. aerospace and automotive), medical (e.g. dental and implants), toys and jewelry have been shown to have the highest utilization of AM technology, ${ }^{9,10}$ supported by strong academic research particularly within transport and medicine. The increasing adoption of AM in these industries is primarily due to the inherent opportunities for customization, weight reduction, and iterative experimentation in low volumes. $5,9,11,12$

Sport is also an industry that is logically suited to the opportunities offered by AM and is frequently mentioned in AM academic literature. 5, 9,11,12 Sporting products are typically mass-produced to suit normative populations e.g. typical athlete heights, weights, foot sizes and limb lengths. As such, products like customized orthotic insoles are often made available to help adjust standard shoes to fit individual anatomies more appropriately, however, in many cases, these "customized" products are also produced in a limited range of sizes and shapes or must be manipulated in a post-hoc fashion via processes like heat molding. Comparatively, AM offers the opportunity to produce truly customized products that fit individual anatomies and performance requirements exactly, thus having potential to improve comfort, mitigate injuries (particularly overuse injuries) and improve performance.

Despite the opportunities, research into the use of AM in sports is limited. Therefore, it is difficult to ascertain whether these theoretical benefits could be realized in practice. Notably, in the limited existing sports AM research, products are rarely supported with detailed case studies or data, with Mawale et al. describing that the sports industry is only at the "initiating phase" of adoption. ${ }^{9}$ A 2019 study of awareness of AM within the sports industry by Meier et al. ${ }^{10}$ suggested limitations such as a lack of functional materials, lack of expertise in designing products for AM and high machine costs remain challenges, despite evidence from other industries of increasing adoption. Furthermore, the study found through literature review and interviews with industry leaders that the sports industry has a general lack of awareness of AM technology, and while the technology is helping to drive innovation in product design, particularly through rapid prototyping (a term used to describe the application of AM technologies for producing prototypes rather than end-use products ${ }^{1}$ ), it is not being implemented in any significant way to drive production of new forms of products and markets.

Contrastingly, online media portrays a different story with sporting applications of 3D printing gaining significant coverage in recent years, including shoes by Nike (e.g. Flyknit ${ }^{13}$ ), Adidas (e.g. Futurecraft $4 \mathrm{D}^{14}$ ) and New Balance (e.g. Zante Generate ${ }^{15}$ ), as well as shin pads, ${ }^{16}$ bicycles, ${ }^{17,} 18$ helmets, ${ }^{19}, 20$ Olympic speed skating gloves, ${ }^{21}$ prosthetics used in the Paralympics ${ }^{22}$ and countless other examples. Carbon (Redwood City, California, USA), creators of Continuous Liquid Interface Production (CLIP) technology, have collaboratively developed three high-profile sports products with leading manufacturers which are currently available to consumers, or planned in the near future: the 
Adidas Futurecraft 4D shoes, ${ }^{14}$ a customizable football helmet liner for Riddell Sports Group ${ }^{23}$ (Des Plaines, IL, USA) and a bicycle saddle called the S-Works Power Saddle for Specialized (Specialized Bicycle Components, Morgan Hill, CA, USA) featuring a lattice structure made up of over 14,000 struts. ${ }^{24}$ While these examples may be the exception within the sports industry for adoption of AM, rather than the rule, their prominence online and growing consumer awareness does portray an increasing adoption for its ability to offer new performance-driven qualities to the market.

Due to the pace of AM innovation, information about new shoes and other products produced through AM are often only available through mainstream news websites and company media releases, rather than more traditional academic sources. This challenge has been acknowledged particularly within formal AM education, with flipped classroom models and project-based learning encouraging the use of various digital resources to inform learning that is current and aligned with industry. ${ }^{25-27}$ Given these contrasting portrayals of AM within sports, this study asked the question what scientific evidence is available that AM provides improved sporting products? The main objectives were to document the types of sports and products utilizing AM, identify the different AM technologies, materials, software and associated digital technologies employed, document the scale of research studies, and synthesize the opportunities and challenges of AM from literature. It was hypothesized that if AM technology is being used to manufacture end-use sporting products for some of the most iconic global brands, then there should be a growing volume of scientific evidence supporting claims of improved performance, comfort or other properties.

To answer this question, a systematic review methodology was employed. Through meta-analysis, this provided an overview of trends related to sporting applications of AM, as well as technical knowledge related to hardware and software used within research. The study provides a roadmap of sports-related AM research since the technology emerged, allowing researchers to understand the current state of the field, and provides direction for future research based on this understanding. Whether AM is supported by researchers, or simply media hype that inflates consumer expectations, this study provides an objective analysis of academic research into sporting applications as the technology transitions from rapid prototyping to increasingly end-use applications.

\section{Method}

This systematic review and meta-analysis was conducted according to the Preferred Reporting Items for Systematic Review and Meta-Analysis Protocols (PRISMA-P) 2015. ${ }^{28}$ The review was conducted across ProQuest, Scopus, Web of Science and SPORTDiscus databases between 17-21 May 2019, with results of each search saved directly to an Endnote library for further analysis. Search results were limited to those published between January 1984 and May 2019 when the search was conducted, with the year 1984 chosen to coincide with the first patents for AM technology filed in Japan, France and the United States of America. ${ }^{3}$ Endnote was chosen for this review process due to the availability of the software, resources, and experience of both authors using the advanced features, as well as the ability to easily share and combine libraries between both authors for the review process.

The terms $3 D$ printing, additive manufacturing and rapid prototyping have often been used interchangeably to describe the technology. ${ }^{1}$ Therefore, literature searches included each of these terms in order to capture all relevant publications. This is evidenced in Table 1 which details all searches conducted within each database for this systematic review. Where possible in the search functions of the four databases, searches were restricted to articles that were peer reviewed and 
written in the English language. Table 1 also shows sports that are similar with results later combined, specifically running/walk*, cycling/bicycl*, soccer/football.

Table 1. Searches conducted in each database, with grayscale used to group similar sports/searches.

\begin{tabular}{|c|c|}
\hline Search Phrase & Search Location \\
\hline ("rapid prototyp*" OR "3d print*" OR "additive manufactur*") AND cycling & \multirow{5}{*}{$\begin{array}{l}\text { Title, abstract, } \\
\text { keywords }\end{array}$} \\
\hline ("rapid prototyp*" OR "3d print*" OR "additive manufactur*") AND danc* & \\
\hline ("rapid prototyp*" OR "3d print*" OR "additive manufactur*") AND running & \\
\hline ("rapid prototyp*" OR "3d print*" OR "additive manufactur*") AND swim* & \\
\hline ("rapid prototyp*" OR "3d print*" OR "additive manufactur*") AND walk* & \\
\hline ("rapid prototyp*" OR "3d print*" OR "additive manufactur*") AND athletic* & \multirow{23}{*}{$\begin{array}{l}\text { Anywhere within } \\
\text { the text of an } \\
\text { article }\end{array}$} \\
\hline ("rapid prototyp*" OR "3d print*" OR "additive manufactur*") AND badminton & \\
\hline ("rapid prototyp*" OR "3d print*" OR "additive manufactur*") AND baseball & \\
\hline ("rapid prototyp*" OR "3d print*" OR "additive manufactur*") AND basketball & \\
\hline ("rapid prototyp*" OR "3d print*" OR "additive manufactur*") AND bicycl* & \\
\hline ("rapid prototyp*" OR "3d print*" OR "additive manufactur*") AND cricket* & \\
\hline ("rapid prototyp*" OR "3d print*" OR "additive manufactur*") AND football & \\
\hline ("rapid prototyp*" OR "3d print*" OR "additive manufactur*") AND golf* & \\
\hline ("rapid prototyp*" OR "3d print*" OR "additive manufactur*") AND gymnastic* & \\
\hline ("rapid prototyp*" OR "3d print*" OR "additive manufactur*") AND hiking & \\
\hline ("rapid prototyp*" OR "3d print*" OR "additive manufactur*") AND hockey & \\
\hline ("rapid prototyp*" OR "3d print*" OR "additive manufactur*") AND "martial art*" & \\
\hline ("rapid prototyp*" OR "3d print*" OR "additive manufactur*") AND netball & \\
\hline $\begin{array}{l}\text { ("rapid prototyp*" OR "3d print*" OR "additive manufactur*") AND "resistance } \\
\text { training" }\end{array}$ & \\
\hline ("rapid prototyp*" OR "3d print*" OR "additive manufactur*") AND rugby & \\
\hline ("rapid prototyp*" OR "3d print*" OR "additive manufactur*") AND soccer & \\
\hline ("rapid prototyp*" OR "3d print*" OR "additive manufactur*") AND sport* & \\
\hline ("rapid prototyp*" OR "3d print*" OR "additive manufactur*") AND "stair climb*" & \\
\hline ("rapid prototyp*" OR "3d print*" OR "additive manufactur*") AND "table tennis" & \\
\hline ("rapid prototyp*" OR "3d print*" OR "additive manufactur*") AND "tai chi" & \\
\hline ("rapid prototyp*" OR "3d print*" OR "additive manufactur*") AND tennis & \\
\hline ("rapid prototyp*" OR "3d print*" OR "additive manufactur*") AND volleyball & \\
\hline ("rapid prototyp*" OR "3d print*" OR "additive manufactur*") AND yoga & \\
\hline
\end{tabular}

The keyword "sport" was used as one of the searches to capture relevant literature which may have spanned multiple sports or contained non-specific titles. To further capture as much relevant literature as possible, the top ten adult sports across six regions of the world were identified from a systematic review by Hulteen et al. ${ }^{29}$ and separately searched within each database. These sports align with statistics from other reports about popular sports, ${ }^{30-32}$ yet an acknowledgement must be made that not every sport in the world could be reasonably searched for this study. Modifications to search keywords from the Hulteen et al. ${ }^{29}$ study included the use of both football and soccer which are used in different regions of the world to describe the same sport, as well as the additional search for bicycle alongside cycling due to the prominence of bicycles as both sporting and recreational products that may be discussed in literature isolated from discussions of the activity of cycling. Running and walking results were also combined due to the similarities in equipment and techniques for these sports, which may also be considered recreational activities. ${ }^{30}$ This resulted in twenty-eight separate searches within each database and comprised of twenty-four distinct sports when running/walking, cycling/bicycle and soccer/football were combined.

Due to "walking" and "running," as well as "cycling," "swimming" and "dancing" also being verbs used to describe other events (e.g. power cycling a computer, or walking a jury through a crime 
scene), limitations were placed on these five searches to results appearing only in the title, keywords or abstract (aka. no full text), whereas all other searches were conducted anywhere within the full-text of an article. Sports with motors were also excluded from this study, for example Formula One and MotoGP, as they were not featured in literature as the most popular sports ${ }^{29-32}$ and their relationship with research to various automotive disciplines would be difficult to separate from research relevant to sporting applications.

After gathering initial search results, duplicates were removed using automatic tools within Endnote. Further duplicates were manually removed from the library in circumstances where different databases classified the same article differently (e.g. conference paper or conference proceeding), or where information was slightly different (e.g. author first and last names in the wrong order). This complete library of results was then independently screened by both authors, assessing article titles and abstracts against inclusion criteria:

1. The article must use AM to produce a functional piece of sporting equipment. This excludes instances of AM used to create prototypes as part of the design process, or studies that focused exclusively on digital simulation (e.g. Finite Element Analysis) of a product design that was intended for AM at a future time.

2. The article must provide quantitative data about the designed product.

3. The equipment must be used during typical sporting activities i.e. training or match play. Supporting products that were medical/rehabilitative in nature were excluded.

4. The article must be original. Review papers that report findings from other studies were excluded.

Articles meeting inclusion criteria by the authors were then combined into a single library and remaining articles were read in full to assess final validity for inclusion. These articles were accessed through the institution libraries of the authors, or where access was restricted, through online repositories of papers and preprints like ResearchGate and academia. Where this was not possible, authors of papers were directly contacted. Papers retained after the full-text review were analyzed in detail using an evidence table to report relevant study characteristics and outcomes reported in this review.

\section{Results}

In total, 11,185 articles were identified through the search, which were reduced to 7,995 articles after removal of duplicates (using both an automated function in Endnote, followed by manual screening for duplicates). Each of the authors screened the complete list of articles using separate methods: One of the authors removed 7,791 articles through methodical screening of titles and abstracts, while the other removed 7,931 using keywords to find articles that did not meet inclusion criteria. When these results were combined ( 268 articles), and duplicates between the two libraries were removed $(n=49)$, 219 articles remained for full-text review. A further 193 articles were removed upon this review for failing to meet inclusion criteria, resulting in 26 articles that met all inclusion criteria. This process is illustrated in Figure 1. 


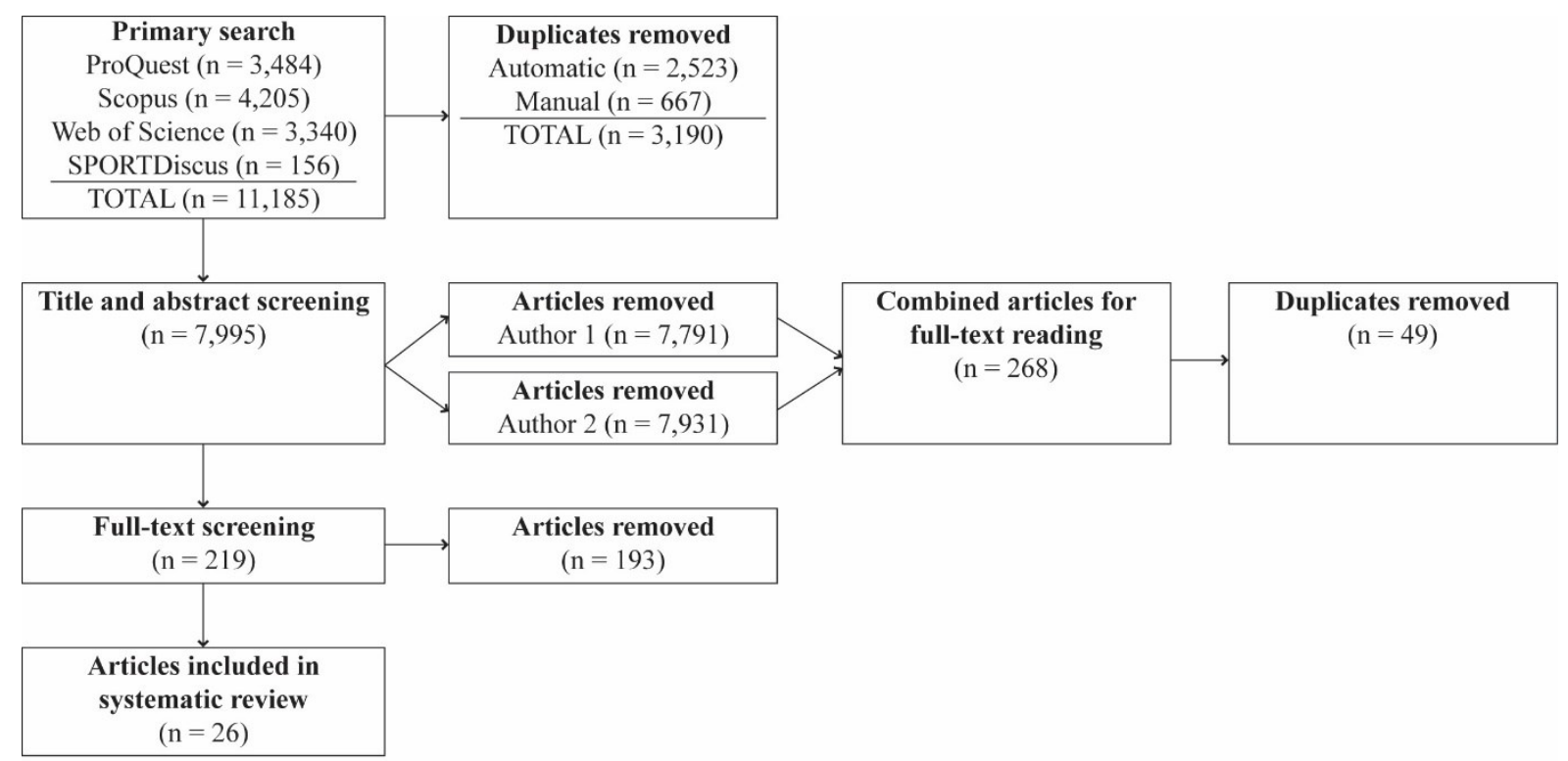

Figure 1. Strategy and results of systematic review at each stage of the process to identify relevant literature.

As shown in Figure 2, articles quantifying improvements in human performance via AM product design did not emerge in academic publications until 2010, twenty-six years after key patents were filed for the technology. In total, between January 2010 and May 2019, eighteen journal articles (69\%), seven conference papers $(27 \%)$ and one book chapter $(4 \%)$ were published, with an average of 2.67 articles published per year (excluding the partial year 2019).

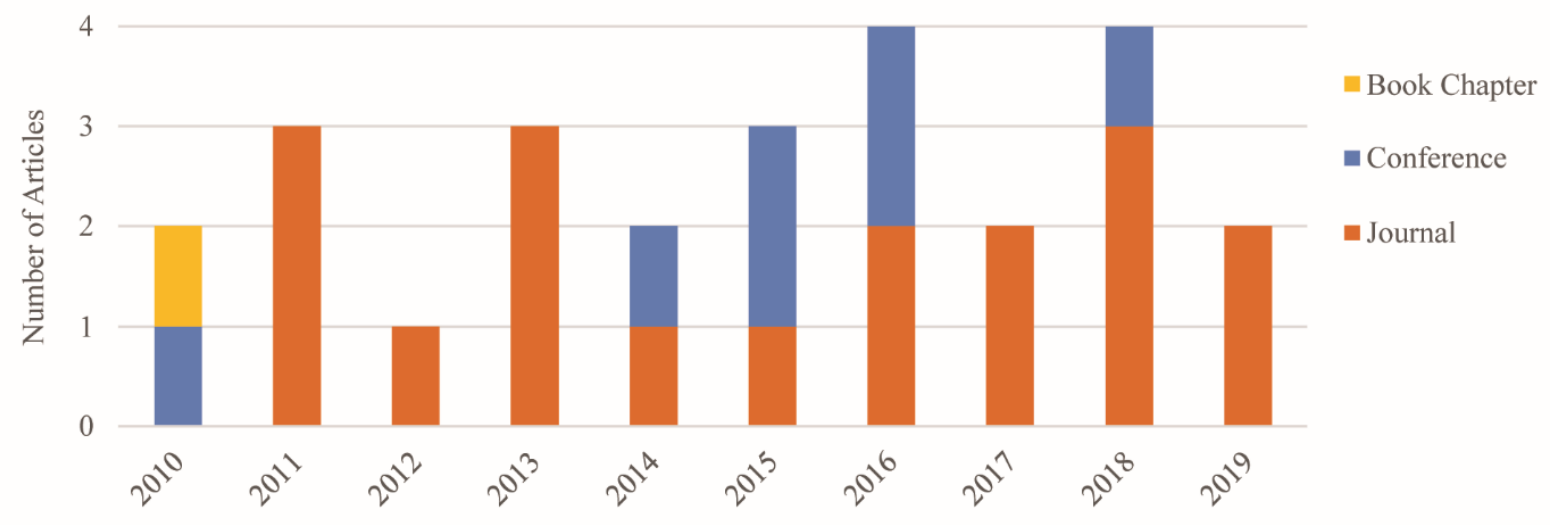

Figure 2. Type of publication by year.

\section{Sports within literature}

Figure 3 shows the sporting activities featured in the literature, with running/walking being the most popular with ten articles (38\%), followed by cycling with four articles $(15 \%)$ and badminton with three articles (12\%). The other sports that were featured only in a single publication were: baseball, climbing, cricket, football (soccer), golf, hurling, in-line skating, rowing and surfing. It is important to note from this data that of the twenty-four discrete sports searched in databases (considering 
groupings in Table 1 and excluding the general term "sport*"), only eight of these sports appeared in the literature (33\%). Despite sixteen other sports being listed in the top ten across different regions of the world, ${ }^{29} 66 \%$ of the specific sport searches did not reveal any articles meeting inclusion criteria. However, four sports that were not specifically searched were identified in the literature: hurling, inline skating, rowing and surfing.

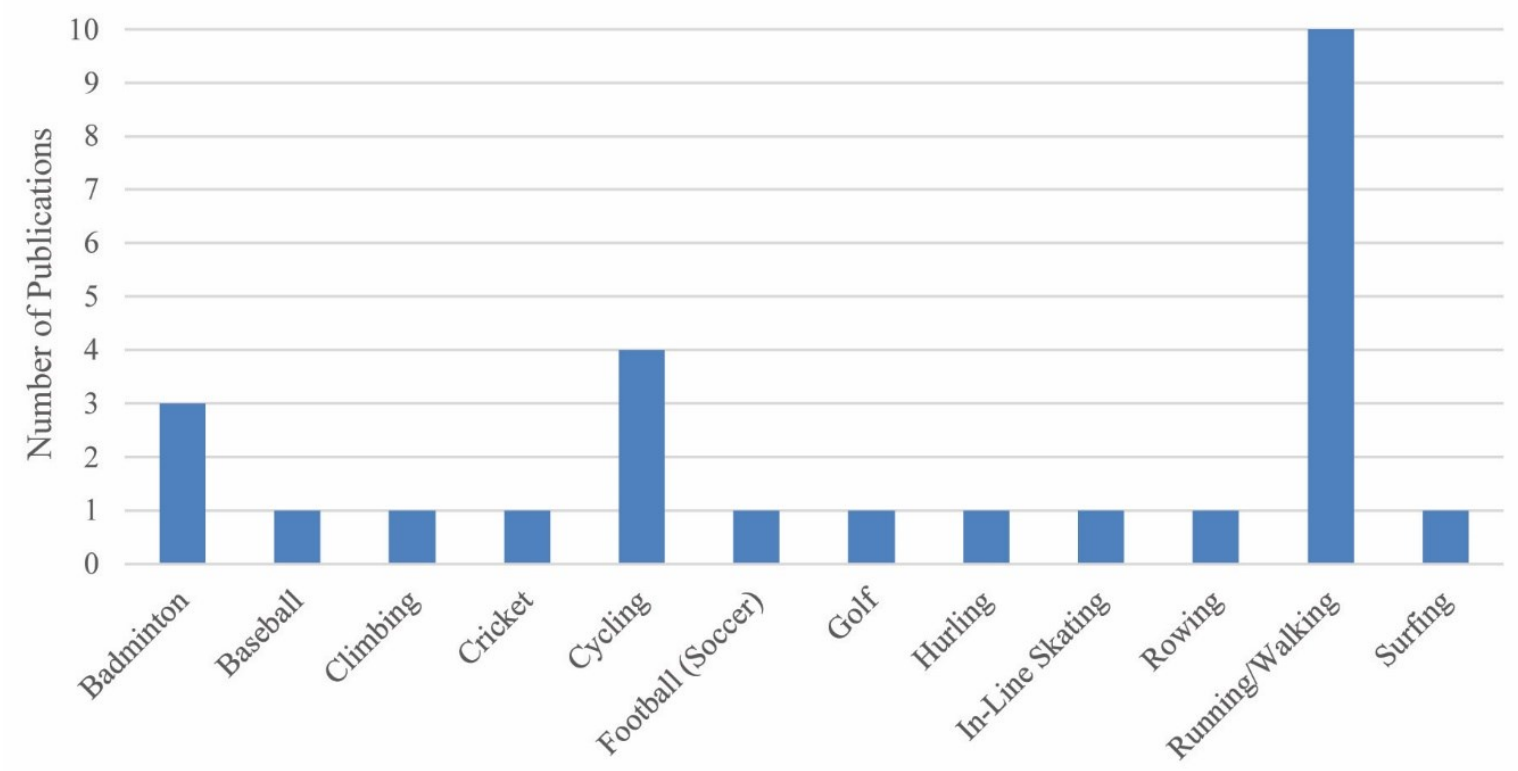

Figure 3. Sports investigated in literature.

While badminton has had three publications investigating the use of AM for shuttlecocks, these publications have been produced by the same authors between $2013-2015,{ }^{33-35}$ indicating that research on this topic has not extended outside of a single research group. Running/walking exhibits a similar trend, with the ten publications produced by four distinct research groups: Salles et al. are responsible for five of the publications investigating insoles, ${ }^{36-40}$ Vinet et al. have three publications on sprint shoes, ${ }^{41-43}$ and the remaining two publications are produced by individual research groups investigating AM of vortex generators on running apparel ${ }^{44}$ and $\mathrm{AM}$ of insoles. ${ }^{45}$ The four articles within the sport of cycling are from discrete research groups. Therefore, cycling and running/walking may be considered to have a similar interest in the application of AM with four unique research groups publishing results within the scope of this literature review. Overall, this means that the twenty-six publications were produced by eighteen unique author groups, potentially indicating limited opportunities or funding for follow-up investigations.

In order to understand the performance properties of additively manufactured sporting products compared to conventionally manufactured products, summarized results from the twenty-six publications are presented in Table 2. The final column provides a quick reference overview comparing whether the AM products provided significant improvements compared to conventional products tested $(\uparrow)$, similar performance $(-)$, or lower performance $(\downarrow)$. Significance was determined through statistical analysis of empirical data and other qualities described within each article. Several articles did not provide comparisons to existing products (N/A) ${ }^{46,47}$ and one article was unable to be accessed through online databases and attempts to directly contact authors. ${ }^{48}$ It is important to note that the criteria used to assess performance in each study is different, and making comparisons between different studies is difficult. For example, depending on the product or feature, "improving" a quality such as aerodynamic performance may be considered negative, as demonstrated in the 
badminton studies where reducing the drag coefficient of a shuttlecock would alter the flight behavior understood by players, negatively impacting play. Therefore, in badminton studies ${ }^{33-35}$ a similar result (-) is considered positive where AM is being investigated to replace the need for waterfowl feathers.

Table 2. Summarized literature results in alphabetical order of sport then year, with overall performance comparison of AM product versus conventional product $(\uparrow-\downarrow)$.

\begin{tabular}{|c|c|c|c|c|}
\hline Reference & Sport & Product & Data Summary & $\uparrow-\downarrow$ \\
\hline $\begin{array}{l}\text { [33] } 2013 \\
\text { Journal }\end{array}$ & Badminton & $\begin{array}{l}\text { Shuttle- } \\
\text { cock }\end{array}$ & $\begin{array}{l}\text { Two shuttlecocks produced with AM exhibited reduced drag } \\
\text { compared to a commercial feather shuttlecock, while another } \\
\text { design was able to achieve similar drag performance. }\end{array}$ & - \\
\hline $\begin{array}{l}{[34] 2014} \\
\text { Conference }\end{array}$ & Badminton & $\begin{array}{l}\text { Shuttle- } \\
\text { cock }\end{array}$ & $\begin{array}{l}\text { Simulation and wind tunnel tests of the AM shuttlecock were } \\
\text { similar to a feather shuttlecock at wind tunnel speeds below } \\
15 \mathrm{~m} / \mathrm{s} \text {. However, they varied significantly at speeds over } \\
15 \mathrm{~m} / \mathrm{s} \text { due to deformation of the skirt. }\end{array}$ & $\downarrow$ \\
\hline $\begin{array}{l}35] 2015 \\
\text { Journal }\end{array}$ & Badminton & $\begin{array}{l}\text { Shuttle- } \\
\text { cock }\end{array}$ & $\begin{array}{l}\text { The AM shuttlecock had a lower drag-to-mass ratio than the } \\
\text { reference feather shuttlecock. The results showed significant } \\
\text { variation in the clear and smash shots due to insufficient drag } \\
\text { on the prototype. The net shot showed good agreement with } \\
\text { the feather shuttlecock. }\end{array}$ & $\downarrow$ \\
\hline $\begin{array}{l}\text { [46] } 2016 \\
\text { Journal }\end{array}$ & Baseball & $\begin{array}{l}\text { Leg } \\
\text { guard }\end{array}$ & $\begin{array}{l}\text { Evaluations of custom leg guards by athletes found them to be } \\
\text { comfortable and effectively protect the legs, although no } \\
\text { comparison was made to an existing product. }\end{array}$ & $\mathrm{N} / \mathrm{A}$ \\
\hline $\begin{array}{l}48] 2015 \\
\text { Conference }\end{array}$ & Climbing & $\begin{array}{l}\text { Fall } \\
\text { arrest }\end{array}$ & Paper could not be accessed & $\mathrm{N} / \mathrm{A}$ \\
\hline $\begin{array}{l}{[49] 2015} \\
\text { Conference }\end{array}$ & Cricket & $\begin{array}{l}\text { Helmet } \\
\text { face } \\
\text { guard }\end{array}$ & $\begin{array}{l}\text { A custom titanium face guard designed for a specific athlete } \\
\text { was able to successfully pass load-bearing tests described by } \\
\text { BS } 7928: 2013 \text { standards. }\end{array}$ & - \\
\hline $\begin{array}{l}50] 2014 \\
\text { Journal }\end{array}$ & $\begin{array}{l}\text { Cycling } \\
\text { (Mountain) }\end{array}$ & $\begin{array}{l}\text { Bicycle } \\
\text { frame }\end{array}$ & $\begin{array}{l}\text { Traditional bike frame } 2100 \mathrm{~g}, \text { AM bike frame } 1400 \mathrm{~g} \text {, overall } \\
33 \% \text { reduction in frame weight. } 44 \% \text { weight reduction in the } \\
\text { seat post bracket. Fatigue testing of the seat post bracket: } 50 \\
000 \text { cycles of } 1200 \mathrm{~N} \text {, achieving } 6 \mathrm{x} \text { the standard. }\end{array}$ & $\bar{l}$ \\
\hline $\begin{array}{l}\text { [51] } 2016 \\
\text { Journal }\end{array}$ & $\begin{array}{l}\text { Cycling } \\
\text { (Mountain) }\end{array}$ & $\begin{array}{l}\text { Bicycle } \\
\text { frame } \\
\text { yoke }\end{array}$ & $\begin{array}{l}\text { A titanium yoke piece produced by CNC machining weighs } \\
136 \mathrm{~g} \text { and costs } \$ 477.50 \text { AUD. A purpose-designed part for AM } \\
\text { has a weight of } 120 \mathrm{~g}(-12 \%) \text { and costs } \$ 193.50 \text { AUD }(-60 \%) \text {. }\end{array}$ & $\bar{\uparrow}$ \\
\hline $\begin{array}{l}52] 2018 \\
\text { Journal }\end{array}$ & Cycling & Crank & $\begin{array}{l}\text { Deformation of AM cranks under static loading was } 7.0 \pm 0.5 \\
\mathrm{~mm} \text { per crank, similar to } 2 \text { commercial cranks. However, the } \\
\text { samples failed critically during fatigue testing at } 2370 \text { and } \\
2620 \text { cycles. }\end{array}$ & $\downarrow$ \\
\hline $\begin{array}{l}19] 2019 \\
\text { Journal }\end{array}$ & Cycling & Helmet & $\begin{array}{l}\text { Several helmets produced with AM featured adjustable } \\
\text { ventilation openings able to vary the overall drag experienced } \\
\text { by a cyclist by up to } 4.1 \% \text { between open and closed positions. } \\
\text { In the closed position a helmet was able to achieve drag area } \\
\text { measurements within } \sim 1 \% \text { of a time trial Kask Bambino with } \\
\text { visor, and within } \sim 2 \% \text { of a Giro Advantage with visor. }\end{array}$ & - \\
\hline $\begin{array}{l}\text { [53] } 2019 \\
\text { Journal }\end{array}$ & $\begin{array}{l}\text { Football } \\
\text { (soccer) }\end{array}$ & $\begin{array}{l}\text { Shin } \\
\text { guard }\end{array}$ & $\begin{array}{l}\text { Using a } 1 \mathrm{~kg} \text { weight with metal stud dropped at a } 400 \mathrm{~mm} \\
\text { height, two AM specimens had acceleration reductions } \\
\text { between } 42 \% \text { and } 68 \% \text { with respect to two commercial shin } \\
\text { guards, while the penetration was reduced } 13 \%-32 \% \text {. The } \\
\text { attenuation and the contact times were similar. }\end{array}$ & $\uparrow$ \\
\hline $\begin{array}{l}{[47] 2016} \\
\text { Conference }\end{array}$ & Golf & $\begin{array}{l}\text { Golf } \\
\text { ball }\end{array}$ & $\begin{array}{l}\text { Eleven golf-balls with various dimple geometries tested in a } \\
\text { wind tunnel found a near linear relationship between relative } \\
\text { roughness and drag coefficient. At } 100 \mathrm{~km} / \mathrm{h} \text {, a ball with } \\
\text { shallower dimples will travel further. }\end{array}$ & $\mathrm{N} / \mathrm{A}$ \\
\hline $\begin{array}{l}\text { [54] } 2018 \\
\text { Journal }\end{array}$ & Hurling & Gloves & $\begin{array}{l}\text { Comfort: Only } 2 / 9 \text { players rated the gloves to be a good } \\
\text { comfort level. Performance: No players indicated that the } \\
\text { glove enhanced performance. Protection level: } 1 / 9 \text { a lot, } 4 / 9 \\
\text { average, } 2 / 9 \text { a little, } 2 / 9 \text { none. }\end{array}$ & $\downarrow$ \\
\hline
\end{tabular}




\begin{tabular}{|c|c|c|c|c|}
\hline $\begin{array}{l}{[55] 2018} \\
\text { Conference }\end{array}$ & $\begin{array}{l}\text { In-line } \\
\text { Skating }\end{array}$ & $\begin{array}{l}\text { Skating } \\
\text { wheels }\end{array}$ & $\begin{array}{l}\text { An in-line skating wheel has a total volume of } 66,900 \mathrm{~mm}^{3} \text {. A } \\
\text { Superformula optimized wheel for AM had an average volume } \\
\text { of } 2,366 \mathrm{~mm}^{3} \text {, with the best result being } 1,985 \mathrm{~mm}^{3} \text {, which is } \\
2.97 \% \text { of the solid wheel volume. }\end{array}$ & $\uparrow$ \\
\hline $\begin{array}{l}56] 2017 \\
\text { Journal }\end{array}$ & Rowing & Insole & $\begin{array}{l}\text { A textured insole produced with AM provided significantly } \\
\text { greater force and contact area at peak force and over the whole } \\
\text { drive phase than the control insoles. In general, power slightly } \\
\text { increased in the range of } 3-11 \mathrm{~W} \text { for one of the AM insoles } \\
\text { compared to the control, and the mean distance travelled was } \\
\text { from } 4-12 \mathrm{~m} \text { longer than that travelled with control insoles, but } \\
\text { were not statistically significant. }\end{array}$ & $\uparrow$ \\
\hline $\begin{array}{l}{[36] 2010} \\
\text { Book } \\
\text { Chapter }\end{array}$ & Running & Insole & $\begin{array}{l}\text { During the first } 1.5 \text { months, the control insole caused } \\
\text { discomfort in } 63 \% \text { of participant training sessions compared } \\
\text { with } 51 \% \text { for the AM insole. In the last } 1.5 \text { months the runners } \\
\text { in the control condition reported some discomfort in } 38 \% \text { of } \\
\text { their training sessions, whereas the participants in the AM } \\
\text { group reported discomfort in } 20 \% \text {. }\end{array}$ & $\uparrow$ \\
\hline $\begin{array}{l}{[42] 2010} \\
\text { Conference }\end{array}$ & $\begin{array}{l}\text { Running } \\
\text { (sprint) }\end{array}$ & Shoes & $\begin{array}{l}\text { An AM sprint spike design was able to generate traction } \\
\text { forces similar to commercially available sprint shoes tested, } \\
\text { across the levels of normal loading examined. }\end{array}$ & - \\
\hline $\begin{array}{l}{[40] 2011} \\
\text { Journal }\end{array}$ & Running & Insole & As [34]. & $\uparrow$ \\
\hline $\begin{array}{l}\text { [41] } 2011 \\
\text { Journal }\end{array}$ & $\begin{array}{l}\text { Running } \\
\text { (sprint) }\end{array}$ & Shoes & $\begin{array}{l}\text { AM shoe soles were able to improve performance in several } \\
\text { tests including: maximum dynamic strength of squat jump } \\
\text { testing ( } 2182 \mathrm{~N} \text { compared with } 1911 \mathrm{~N} \text { for the control) and } \\
\text { ankle power ( } 307.5 \mathrm{~W} \text { compared with } 264.4 \mathrm{~W} \text { for the control), } \\
\text { as well as results for bounce drop testing. }\end{array}$ & $\uparrow$ \\
\hline $\begin{array}{l}{[43] 2011} \\
\text { Journal }\end{array}$ & $\begin{array}{l}\text { Running } \\
\text { (sprint) }\end{array}$ & Shoes & $\begin{array}{l}\text { The "needle and pin" concept sole was the best performing } \\
\text { design, achieving } 0.6 \% \text { more peak traction force than the worst } \\
\text { performing commercial shoe (Adidas) at a } 500 \mathrm{~N} \text { load, } \\
\text { however, in general the AM concept shoes generated lower } \\
\text { mean peak static forces than the commercially available sprint } \\
\text { shoes. }\end{array}$ & $\downarrow$ \\
\hline $\begin{array}{l}\text { [37] } 2012 \\
\text { Journal }\end{array}$ & Running & Insole & $\begin{array}{l}\text { The mean ratings for foot discomfort variables were low for } \\
\text { both standard and AM insoles, but statistical analysis showed } \\
\text { no significant differences between the two conditions. }\end{array}$ & - \\
\hline $\begin{array}{l}{[38] 2013} \\
\text { Journal }\end{array}$ & Running & Insole & As [35]. & - \\
\hline $\begin{array}{l}{[39] 2013} \\
\text { Journal }\end{array}$ & Running & Insole & $\begin{array}{l}\text { AM insoles had less reported discomfort when compared to } \\
\text { the control for all measured aspects of the foot regions. For the } \\
\text { heel and fit, significant differences between conditions were } \\
\text { detected, whilst for the forefoot and midfoot the difference } \\
\text { was approaching significance. }\end{array}$ & $\uparrow$ \\
\hline $\begin{array}{l}{[44] 2016} \\
\text { Conference }\end{array}$ & Running & Apparel & $\begin{array}{l}\text { With vortex generators directly 3D printed onto race apparel, } \\
\text { aerodynamic drag }\left(\mathrm{F}_{\mathrm{d}}\right) \text { forces were reduced between } 3.7 \text { and } \\
6.8 \% \text { compared to equivalent advanced race apparel developed } \\
\text { for the } 2012 \text { London Olympics. }\end{array}$ & $\uparrow$ \\
\hline $\begin{array}{l}{[45] 2018} \\
\text { Journal }\end{array}$ & $\begin{array}{l}\text { Running / } \\
\text { Walking }\end{array}$ & Insole & $\begin{array}{l}\text { The effects of wearing a customized 3D-printed insole was not } \\
\text { significantly different from those of a ready-made insole } \\
\text { regardless of walking/running speed. }\end{array}$ & \\
\hline $\begin{array}{l}\text { [57] } 2017 \\
\text { Journal }\end{array}$ & Surfing & $\begin{array}{l}\text { Surf } \\
\text { fins }\end{array}$ & $\begin{array}{l}\text { The performance of a surfboard with AM fins was similar to } \\
\text { the performance of a surfboard using commercial fins. }\end{array}$ & \\
\hline
\end{tabular}

Key: $\uparrow=$ improved performance; $\downarrow=$ reduced performance; - = similar performance (may be a positive result where the intent was to achieve the same performance using different methods/materials); N/A = not applicable.

From the data in Table 2, the number of articles that found an improved performance of AM products compared to conventional products was ten (38\%). Eight articles (31\%) found a similar performance (which may also be considered positive depending on the study intent), five articles (19\%) found a 
lower performance, and three articles (12\%) did not provide comparison outside of products produced. This data is visualized in Figure 4. From the specific products investigated within the literature it is also possible to classify them into three broad categories: Equipment that is essential to the sport, including balls, bicycles and shoes $(\mathrm{n}=14,54 \%)$, products designed to enhance comfort, fitting and/or reduce injury risk, specifically insoles $(n=7,27 \%)$, and products that provide protection such as helmets and shin guards $(n=5,19 \%)$. This is visualized in Figure 5.

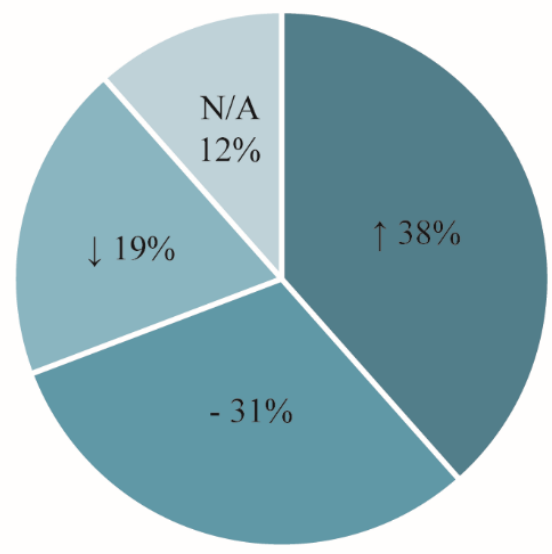

Figure 4. Overall advantage $(\uparrow)$, similarity $(-)$, disadvantage $(\downarrow)$ between AM and conventional products summarized from Table 2 . N/A denotes articles that did not provide comparison to existing products.

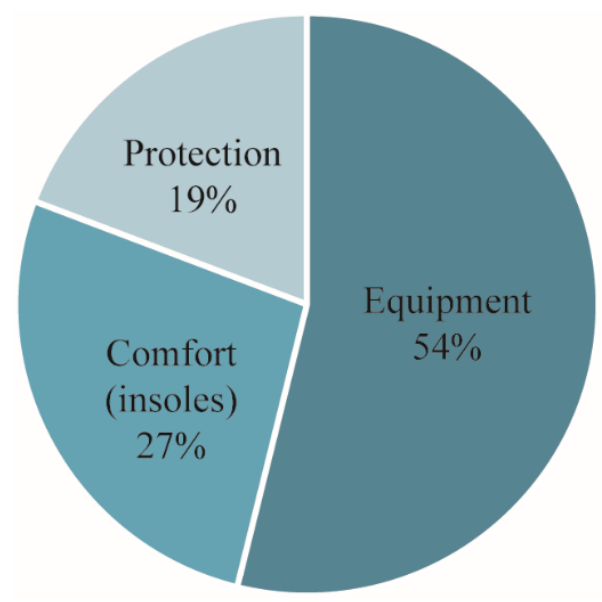

Figure 5. Categories of products within literature summarized from Table 2.

\section{Additive Manufacturing and Associated Technologies}

From a technical perspective Table 3 summarizes the CAD software, AM technologies, materials and other technologies employed in each study. The type of AM technology has been graphed in Figure 6, showing that selective laser sintering (SLS) featured in nine articles (33\%), which was the most used technology, followed by material jetting (MJ) with six articles (22\%), fused filament fabrication (FFF) and selective laser melting (SLM) with four articles each (15\%), binder jetting (BJ) with one article $(4 \%)$, and three articles $(11 \%)$ which used a resin or polymer process that was not specifically 
described (although visually appeared to be either MJ or stereolithography). Considering the International ASTM 52900 standards classifying AM technologies, ${ }^{1}$ SLS and SLM fall under the Powder Bed Fusion category, meaning that thirteen articles (50\%) of articles used this technology.

Table 3. Summary of software and 3D printers used in articles.

\begin{tabular}{|c|c|c|c|c|c|}
\hline Reference & CAD Software & 3D Printer & Type & Material & Other Technology \\
\hline $\begin{array}{l}33] 2013 \\
\text { Journal }\end{array}$ & - & $\begin{array}{l}\text { Objet Eden } \\
350 \mathrm{~V}\end{array}$ & MJ & $\begin{array}{l}\text { FullCure } 720 \text { (model } \\
\text { material) and FullCure } \\
705 \text { (support material) }\end{array}$ & $\begin{array}{l}\text { ANSYS CFX for } \\
\text { computational fluid } \\
\text { dynamics }\end{array}$ \\
\hline $\begin{array}{l}{[34] 2014} \\
\text { Conference }\end{array}$ & - & $\begin{array}{l}\text { Objet Eden } \\
350 \mathrm{~V}\end{array}$ & MJ & $\begin{array}{l}\text { FullCure } 720 \text { (model } \\
\text { material) and FullCure } \\
705 \text { (support material) }\end{array}$ & $\begin{array}{l}\text { ANSYS CFX for } \\
\text { computational fluid } \\
\text { dynamics }\end{array}$ \\
\hline $\begin{array}{l}{[35] 2015} \\
\text { Journal }\end{array}$ & - & - & - & Undisclosed polymer & $\begin{array}{l}\text { MATLAB for flight } \\
\text { path calculations }\end{array}$ \\
\hline $\begin{array}{l}46] 2016 \\
\text { Journal }\end{array}$ & $\begin{array}{l}\text { Geomagic } \\
\text { Design }\end{array}$ & Zcorp z650 & BJ & zp150 (plaster) powder & $\begin{array}{l}\text { Artec MHT 3D } \\
\text { scanner }\end{array}$ \\
\hline $\begin{array}{l}\text { [48] } 2015 \\
\text { Conference }\end{array}$ & - & - & - & - & - \\
\hline $\begin{array}{l}\text { [49] } 2015 \\
\text { Conference }\end{array}$ & - & - & SLM & Titanium $(\mathrm{Ti}-6 \mathrm{Al}-4 \mathrm{~V})$ & - \\
\hline $\begin{array}{l}{[50] 2014} \\
\text { Journal }\end{array}$ & $\begin{array}{l}\text { Altair } \\
\text { SolidThinking } \\
\text { Inspire }\end{array}$ & $\begin{array}{l}\text { Renishaw } \\
\text { AM250 }\end{array}$ & SLM & Titanium alloy & - \\
\hline $\begin{array}{l}{[51] 2016} \\
\text { Journal }\end{array}$ & $\begin{array}{l}\text { Geomagic, } \\
\text { Solidworks }\end{array}$ & $\begin{array}{l}\text { SLM Solutions } \\
\text { SLM125 }\end{array}$ & SLM & Titanium & $\begin{array}{l}\text { Autodesk Mechanical } \\
\text { Simulation, Creaform } \\
\text { EXAscan 3D scanner }\end{array}$ \\
\hline $\begin{array}{l}52] 2018 \\
\text { Journal }\end{array}$ & $\begin{array}{l}\text { Genesis Design } \\
\text { Studio 14.0, } \\
\text { Solidworks, } \\
\text { Magics } 19.0\end{array}$ & EOS M280 & SLM & Titanium Ti64 & $\begin{array}{l}\text { HyperMesh 13.0, CT } \\
\text { scanner }\end{array}$ \\
\hline $\begin{array}{l}{[19] 2019} \\
\text { Journal }\end{array}$ & Solidworks & $\begin{array}{l}\text { Undisclosed, } \\
\text { Wanhao } \\
\text { Duplicator i3 }\end{array}$ & $\begin{array}{l}\text { SLS, } \\
\text { FFF }\end{array}$ & $\begin{array}{l}\text { Polyamide (nylon), } \\
\text { ABS }\end{array}$ & 3D scanner \\
\hline $\begin{array}{l}53] 2019 \\
\text { Journal }\end{array}$ & $\begin{array}{l}\text { CREO 3.0, } \\
\text { Rhinoceros } 5.0\end{array}$ & $\begin{array}{l}\text { Objet Connex } 3 \\
260\end{array}$ & MJ & $\begin{array}{l}\text { FullCure } 720 \text { (rigid } \\
\text { parts), FullCure } 930 \\
\text { (lattice structure), } \\
\text { FullCure } 705 \text { (support } \\
\text { material) }\end{array}$ & $\begin{array}{l}\text { 3D Systems Sense } \\
\text { 3D scanner }\end{array}$ \\
\hline $\begin{array}{l}\text { [47] } 2016 \\
\text { Conference }\end{array}$ & CATIA & - & - & Resin & - \\
\hline $\begin{array}{l}54] 2018 \\
\text { Journal }\end{array}$ & $\begin{array}{l}\text { Geomagic } \\
\text { Studio }\end{array}$ & $\begin{array}{l}\text { MakerBot } \\
\text { Replicator } 2\end{array}$ & FFF & NinjaFlex (TPU), PLA & $\begin{array}{l}\text { 3D Systems Sense } \\
\text { 3D scanner }\end{array}$ \\
\hline $\begin{array}{l}{[55] 2018} \\
\text { Conference }\end{array}$ & $\begin{array}{l}\text { MATLAB, } \\
\text { JIGSAW mesh } \\
\text { generator }\end{array}$ & $\begin{array}{l}\text { Stratasys } \\
\text { Objet500 } \\
\text { Connex3 }\end{array}$ & MJ & VeroWhite (resin) & - \\
\hline $\begin{array}{l}\text { [56] } 2017 \\
\text { Journal }\end{array}$ & - & - & MJ & $\begin{array}{l}\text { Stratasys photopolymer } \\
\text { MED610 }\end{array}$ & $\begin{array}{l}\text { MATLAB for data } \\
\text { analysis }\end{array}$ \\
\hline $\begin{array}{l}{[36] 2010} \\
\text { Book } \\
\text { Chapter }\end{array}$ & $\begin{array}{l}\text { Geomagic } \\
\text { Studio }\end{array}$ & - & SLS & $\begin{array}{l}\text { DuraForm Polyamide } \\
\text { (nylon) }\end{array}$ & $\begin{array}{l}\text { RealScan USB } 200 \\
\text { 3D Scanner }\end{array}$ \\
\hline $\begin{array}{l}\text { [42] } 2010 \\
\text { Conference }\end{array}$ & - & - & SLS & Polyamide 12 (nylon) & - \\
\hline $\begin{array}{l}{[40] 2011} \\
\text { Journal }\end{array}$ & $\begin{array}{l}\text { Geomagic } \\
\text { Studio }\end{array}$ & - & SLS & $\begin{array}{l}\text { DuraForm Polyamide } \\
\text { (nylon) }\end{array}$ & $\begin{array}{l}\text { RealScan USB } 200 \\
\text { 3D Scanner }\end{array}$ \\
\hline $\begin{array}{l}{[41] 2011} \\
\text { Journal }\end{array}$ & - & - & SLS & Polyamide 12 (nylon) & - \\
\hline $\begin{array}{l}{[43] 2011} \\
\text { Journal }\end{array}$ & Solidworks & EOS P390 & SLS & Polyamide 12 (nylon) & - \\
\hline
\end{tabular}




\begin{tabular}{|c|c|c|c|c|c|}
\hline $\begin{array}{l}\text { [37] } 2012 \\
\text { Journal }\end{array}$ & Magics & - & SLS & $\begin{array}{l}\text { DuraForm Polyamide } \\
\text { (nylon) }\end{array}$ & $\begin{array}{l}\text { eScan 200 3D } \\
\text { scanner }\end{array}$ \\
\hline $\begin{array}{l}{[38] 2013} \\
\text { Journal }\end{array}$ & Magics & - & SLS & $\begin{array}{l}\text { DuraForm Polyamide } \\
\text { (nylon) }\end{array}$ & $\begin{array}{l}\text { eScan } 2003 \mathrm{D} \\
\text { scanner }\end{array}$ \\
\hline $\begin{array}{l}\text { [39] } 2013 \\
\text { Journal }\end{array}$ & $\begin{array}{l}\text { Geomagic } \\
\text { Studio }\end{array}$ & - & SLS & $\begin{array}{l}\text { DuraForm Polyamide } \\
\text { (nylon) }\end{array}$ & $\begin{array}{l}\text { RealScan USB } 200 \\
\text { 3D Scanner }\end{array}$ \\
\hline $\begin{array}{l}{[44] 2016} \\
\text { Conference }\end{array}$ & - & - & - & Undisclosed polymer & - \\
\hline $\begin{array}{l}\text { [45] } 2018 \\
\text { Journal }\end{array}$ & $\begin{array}{l}\text { Meshmixer, } \\
\text { Gensole, } \\
\text { Solidworks }\end{array}$ & $\begin{array}{l}\text { Cubicon 3DP- } \\
110 \mathrm{~F}\end{array}$ & FFF & - & $\begin{array}{l}\text { EinScan Pro 3D } \\
\text { scanner }\end{array}$ \\
\hline $\begin{array}{l}57] 2017 \\
\text { Journal }\end{array}$ & Solidworks & $\begin{array}{l}\text { Objet Connex } \\
350 . \\
\text { Markforged } \\
\text { Mark Two, } \\
\text { Dimension } \\
\text { uPrintPlus, } \\
\text { Fortus } 900\end{array}$ & $\begin{array}{l}\text { MJ } \\
\text { FFF }\end{array}$ & $\begin{array}{l}\text { ULTEM resin } \\
\text { ABS, carbon fiber } \\
\text { composite }\end{array}$ & - \\
\hline
\end{tabular}

Abbreviations: $\mathrm{BJ}=$ binder jetting, FFF = fused filament fabrication, $\mathrm{MJ}=$ material jetting, $\mathrm{SLM}=$ selective laser melting, SLS = selective laser sintering

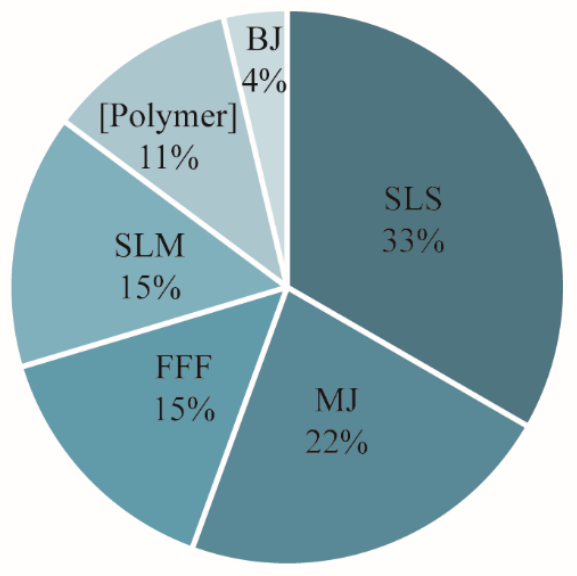

Figure 6. AM technologies used to manufacture products.

All SLM studies utilized titanium, and all SLS studies utilized polyamide (nylon) materials. FullCure 720 was the next most popular material used in three articles (12\%) on Stratasys Objet machines, followed by Acrylonitrile Butadiene Styrene (ABS) in two articles (8\%) and all other materials in Table 3 only appeared once. Four of the articles $(16 \%)$ did not specify the material used.

A broad range of CAD software has been used to design and optimize products within the studies, with the most popular being Solidworks and Geomagic (various versions) which were each used in six articles $(23 \%)$, followed by Magics $(n=3,12 \%)$, and several other software packages which may be common for design engineers (e.g. Rhinoceros and CREO), or specific to certain industries (e.g. Gensole). Nine articles (35\%) did not provide any indication of what software was used to design or optimize products. This oversight presents difficulties for follow-up investigations by external researchers, and journal editors and reviewers should be encouraged to require complete methodologies in future. 
An important finding from this review was the use of 3D scanning within articles to complement the design and optimization of sporting products. Eleven articles (42\%) used a 3D scanner to capture personalized human geometry such as legs for baseball ${ }^{46}$ and football (soccer) leg guards,${ }^{53}$ or feet for personalized insoles. ${ }^{36-40,45}$ This shows a strong relationship between these digital technologies.

Opportunities and limitations identified within each study were also collected, and the recurring findings are listed below:

- Opportunities:

- Combined with 3D scanning, AM provides new cost-effective means for producing athlete-specific products ${ }^{36,39,40,46,53,54}$

- Parametric CAD files allow for almost limitless iterations of a design to suit specific users and conditions ${ }^{19,41,42,50,51,56,57}$

- Part consolidation to reduce assembly costs and open new possibilities with multimaterial $\mathrm{AM}^{51,53,54}$

- Complex geometries that would not be manufacturable using subtractive methods provide new opportunities to improve performance ${ }^{42,44,55}$

- Challenges:

○ Long-term durability of AM materials for sports applications is unclear, with most studies not containing longitudinal analyses, and featuring limited sample sizes $33,35,42$, 53

- AM is typically a slower process than traditional manufacturing processes ${ }^{51,54}$

- Postprocessing can be time- and labor-intensive ${ }^{52,54}$

- Many parts produced with AM must still interface with a conventional part to form a product, limiting geometry ${ }^{49,51}$

- Optimization software still requires manual intervention and an understanding of design for $\mathrm{AM}^{52,55}$

- New products produced through AM may not meet sporting regulations ${ }^{19,44}$

- Laboratory testing may not translate to real-world conditions ${ }^{19,34,56}$

\section{Discussion}

Across all literature included in this review it was clear that authors held an optimistic opinion of AM as it relates to sporting applications, despite results that may have been on par with, or performing worse than, conventional products. Collectively, AM was used in attempts to develop products that improved safety and comfort, ${ }^{36,39,46,49}$ improved performance, ${ }^{19,41,50-52}$ or utilized an alternative production method and material to achieve the same outcome. ${ }^{33-35}$ However, there was no evidence of scientific studies supporting the development of mainstream products for companies like Adidas, and no evidence of the bespoke products developed in the literature leading to new commercial products. Academic and commercial developments of additively manufactured sporting products appear to be occurring separately, and collaborations between academia and industry are likely to be protected by intellectual property (IP) non-disclosure agreements. IP is a complex issue for AM, particularly due to the digital nature of the technology that makes copying, sharing and modifying files relatively easy. ${ }^{58}$ It is further complicated by the opportunity for personalized products, as with many of the products identified through this review, especially when those designs are based off someone's own body data. This is an area of interest for future research. 
The more mature medical AM field provides a useful contextual comparison in order to address the research question of this study, with the opportunities for personalized products to improve health and recovery sharing much in common with sports, and opportunities to utilize other digital technologies like 3D scanning, as well as computed tomography (CT) or magnetic resonance imaging (MRI), well documented.$^{59}$ A 2016 study by Tack et al. ${ }^{60}$ investigated the use of AM in surgical cases, where studies had featured three or more cases or clinical trials, finding 227 papers for review. A similar 2016 study which excluded articles related to bioprinting, dentistry and limb prosthetics analyzed 158 studies, ${ }^{61}$ while another specific to plastic and reconstructive surgery analyzed 103 articles. ${ }^{62}$ A more focused systematic review of AM for patient-specific surgical guides reviewed 38 publications, ${ }^{59}$ while another on patient-specific immobilization devices used in radiotherapy treatments found $18 .^{63}$ Compared to these reviews of medical applications, where the average number of papers reviewed was 131, this broad systematic review of AM for sports applications with only 26 publications is significantly smaller than medical applications and reinforces comments by Mawale et al. ${ }^{9}$ that research into sports applications is only at the "initiating phase" compared to the more established medical industry.

A finding that is common between this review and others conducted within medical systematic reviews is the growth in AM research around the year 2010. Tack et al ${ }^{60}$ identified 30 relevant publications between 2006-2010, compared with the period 2011-2015 which found 189. Popescu et al. ${ }^{59}$ also noted an increase in literature following the 2009 expiry of key Fused Deposition Modeling (FDM) patents, although the authors acknowledge there was no specific evidence to support this correlation. Data from Martelli et al.$^{61}$ showed a slightly earlier growth in research starting in 2007, with the previous two years only revealing 3 studies per year, compared to 16 published in 2007, an annual number that has been maintained, or slightly increased, since this time. Therefore, while the number of articles published on sporting applications is significantly lower than medical applications, the recent growth around the year 2010 supports evidence that improving technologies, materials and access to AM is driving research across industries. ${ }^{5,64}$

Further evidence of sports applications being a relatively new area of academic research is in the spread of literature; other than cycling and running/walking, all sports meeting inclusion criteria have been featured in a single study, or in the case of Badminton, several studies by the same author group. As a result, research findings have not been validated by multiple research groups, and concepts have not been developed by many different researchers to build a body of evidence supporting the use of AM for a particular application. The extent of testing within the literature also suggests the development of sports products for AM are preliminary concepts, with several studies resulting in critical failure of parts, ${ }^{42,43,52,53,57}$ while some studies featured a single sample for testing (although may have included several iterations for simulated tests). ${ }^{34,35,51}$ In order to reach the level of acceptance and innovation experienced within the medical industry, consistent and ongoing research is required by sporting product designers within academia and industry, and value must be placed on funding research that may improve the safety, comfort and performance of athletes at all levels of competition and recreation. This includes clearer reporting in literature of the hypothesis or goals for AM products, and whether achieving a comparable performance attribute to a standard product is desirable.

To support this growth, research must aim to better report methods and technologies within publications. As described previously, $11 \%$ of articles did not report the type of print technology employed to produce parts and $16 \%$ of articles did not report the material used. Furthermore, as shown in Table 3, 36\% $(\mathrm{n}=9)$ of articles did not describe any software used to design or optimize 
products and $52 \%(n=13)$ of articles did not name the 3D printer used. Such reporting is critical to the reproducibility of research and has been discussed as a current issue by Gao et al., ${ }^{64}$ alongside issues of variations between AM technologies, limiting the ability for researchers to build new experiments to either validate or progress published material.

It is important to note that while rigorous in methodology, this review did not search through a large number of databases, and as a result, it is possible that some relevant literature was not uncovered. It is also possible that the search phrases, which included both general sports keywords as well as specific ones, missed some studies that may have been extremely specific in their research focus, or published in conference proceedings not indexed within major academic databases. However, it is unlikely that any missing articles would significantly alter the findings and recommendations of this research, and the methodology employed will allow future follow-up studies to accurately measure changes over time.

\section{Conclusion}

As a result of this study it is possible to conclude that additive manufacturing has yet to become a hit within academia for sporting applications. Despite exemplars frequenting 3D printing and additive manufacturing news websites, manufacturing trade shows and conferences, little scientific evidence exists to support the adoption of AM to produce sports products, with only twenty-six peer reviewed articles identified up until May 2019. Overall, twelve different sports were identified as having been the focus of new additively manufactured products with only badminton, cycling and running/walking being featured in more than a single article. This indicates a broad interest in applications of AM in sport, but with potentially limited opportunities or funding for follow-up investigations. The results also indicate the relatively recent emergence of sports as a research focus, with empirical evidence published beginning in 2010 despite earlier discussions within broader AM literature about the good alignment of AM opportunities with sporting applications. Through objective collation of the evidence to-date, this research cuts through the hype surrounding the use of AM to manufacture sporting products and highlights the need for rigorous, sustained and ongoing research in order to support manufacturers, product designers and athletes of all experience levels.

\section{Declaration of Conflicting Interests}

The author(s) declared no potential conflicts of interest with respect to the research, authorship and/or publication of this article.

\section{Funding}

The author(s) received no financial support for the research, authorship and/or publication of this article.

\section{Supplementary Data}

Data are available under the terms of the Creative Commons Attribution 4.0 International license (CC-BY 4.0).

\section{References}

1. ISO/ASTM 52900: Additive Manufacturing - General Principles - Terminology. 
2. Wohlers T, Campbell I, Huff R, Diegel O and Kowen J. (2019). Wohlers Report 2019: 3D Printing and Additive Manufacturing State of the Industry. Fort Collins, CO, USA: Wohlers Associates, 2019.

3. Gibson I, Rosen D and Stucker B. Additive Manufacturing Technologies: 3D Printing, Rapid Prototyping, and Direct Digital Manufacturing. 2 ed. New York: Springer, 2015.

4. Murray CJ. 3D Systems going mainstream in heathcare: 3D printing is becoming a go-to for customized healthcare solutions. Design News. 2015, p. 27-28.

5. Quinlan HE, Hasan T, Jaddou J, et al. Industrial and Consumer Uses of Additive Manufacturing: A Discussion of Capabilities, Trajectories, and Challenges. Journal of Industrial Ecology 2017; 21: S15-S20. DOI: doi:10.1111/jiec.12609.

6. Sandström CG. The non-disruptive emergence of an ecosystem for 3D Printing - Insights from the hearing aid industry's transition 1989-2008. Technological Forecasting and Social Change 2016; 102: 160-168. DOI: 10.1016/j.techfore.2015.09.006.

7. Murr LE. Additive manufacturing of biomedical devices: an overview. Materials Technology 2018; 33: 57-70. DOI: 10.1080/10667857.2017.1389052.

8. Kumar LJ and Krishnadas Nair CG. Current Trends of Additive Manufacturing in the Aerospace Industry. In: Wimpenny DI, Pandey PM and Kumar LJ (eds) Advances in 3D Printing \& Additive Manufacturing Technologies. Singapore: Springer, 2017, pp.39-54.

9. Mawale MB, Kuthe AM and Dahake SW. Additive layered manufacturing: State-of-the-art applications in product innovation. Concurrent Engineering 2016; 24: 94-102. DOI: $10.1177 / 1063293 X 15613111$.

10. Meier M, Tan K, Lim M, et al. Unlocking innovation in the sport industry through additive manufacturing. Business Process Management Journal 2019; 25: 456-475. DOI: 10.1108/BPMJ10-2017-0285.

11. D'Aveni R. The 3-D Printing Revolution. Harvard Business Review. 2015, p. 40-48.

12. Novak JI and Bardini P. The Popular Culture of 3D Printing: When the Digital Gets Physical. In: Ozgen O (ed) Handbook of Research on Consumption, Media, and Popular Culture in the Global Age. Hershey, PA, USA: IGI Global, 2019, pp.188-211.

13. Deng V. Nike Updates Its 'Fastest Shoe In the World' With a New 3D-Printed Upper, https://footwearnews.com/2018/shop/sneakers-deals/nike-3d-printed-vaporfly-elite-flyprint1202701622/ (2018, accessed 12 September 2019).

14. Heater B. Adidas joins Carbon's board as its 3D printed shoes finally drop, https://techcrunch.com/2018/01/18/adidas-joins-carbons-board-as-its-3d-printed-shoes-finallydrop/ (2018, accessed 17 March 2019).

15. Saunders S. New Balance Uses Ultrasonic Equipment and Sieves to Ensure High Powder Throughput For 3D Printed Midsoles, https://3dprint.com/199087/new-balance-powder-casestudy/ (2018, accessed 28 September 2019).

16. Grunewald SJ. High-Tech Zweikampf 3D Printed Soccer Shin Guards Get Kickstarted, https://3dprint.com/130326/3d-printed-shin-guards/ (2016, accessed 12 September 2019).

17. Howarth D. Arc Bicycle has 3D-printed steel frame created by TU Delft students and MX3D, https://www.dezeen.com/2016/02/04/arc-bicycle-3d-printed-steel-frame-amsterdam-tu-delft-mx3d/ (2016, accessed 28 September 2019).

18. Novak JI. A Study of Bicycle Frame Customisation Through the use of Additive Manufacturing Technology. RAPID 2015. Long Beach, California: SME, 2015.

19. Novak J, Burton D and Crouch T. Aerodynamic test results of bicycle helmets in different configurations: Towards a responsive design. Proceedings of the Institution of Mechanical 
Engineers, Part P: Journal of Sports Engineering and Technology 2019; 233: 268-276. DOI: $10.1177 / 1754337118822613$.

20. Vialva T. Hexo Helmets releases custom 3D printed bicycle helmets with optimized impact resistance, https://3dprintingindustry.com/news/hexo-helmets-releases-custom-3d-printed-bicyclehelmets-with-optimized-impact-resistance-148332/ (2019, accessed 12 September 2019).

21. Scott C. 3D Printing Helped Chinese Team Win Gold at 2018 Winter Olympics, https://3dprint.com/206664/3d-printing-olympics-gold/ (2018, accessed 20 September 2018).

22. Mahon L. First 3D Printed Paralympic Cycling Prosthetic to Compete in Rio, https://3dprintingindustry.com/news/first-3d-printed-paralympic-cycling-prosthetic-compete-rio91614/ (2016, accessed 12 September 2019).

23. Heater B. Carbon is 3D printing custom football helmet liners for Riddell, https://techcrunch.com/2019/02/01/carbon-is-3d-printing-custom-football-helmet-liners-forriddell/ (2019, accessed 28 September 2019).

24. Jackson B. New for consumers: Carbon and Specialized 3D print superior comfort bike saddle, https://3dprintingindustry.com/news/new-for-consumers-carbon-and-specialized-3d-print-superiorcomfort-bike-saddle-160852/ (2019, accessed 12 September 2019).

25. Loy J. eLearning and eMaking: 3D Printing Blurring the Digital and the Physical. Education Sciences 2014; 4: 108. DOI: 10.3390/educsci4010108.

26. Novak JI. Re-Educating the Educators: Collaborative 3D Printing Education. In: Santos IM, Ali $\mathrm{N}$, Areepattamannil S, (eds) Interdisciplinary and International Perspectives on $3 D$ Printing in Education. Hershey, PA, USA: IGI Global, 2019, pp.28-49.

27. Trust T and Maloy RW. Why 3D Print? The 21st-Century Skills Students Develop While Engaging in 3D Printing Projects. Computers in the Schools 2017; 34: 253-266. DOI: 10.1080/07380569.2017.1384684.

28. Moher D, Shamseer L, Clarke M, et al. Preferred reporting items for systematic review and metaanalysis protocols (PRISMA-P) 2015 statement. Systematic Reviews 2015; 4. DOI: 10.1186/20464053-4-1.

29. Hulteen RM, Smith JJ, Morgan PJ, et al. Global participation in sport and leisure-time physical activities: A systematic review and meta-analysis. Preventive Medicine 2017; 95: 14-25. DOI: 10.1016/j.ypmed.2016.11.027.

30. Bottenburg Mv, Rijnen B and Sterkenburg J. Sports participation in the European Union: Trends and differences. Nieuwegein/'s-Hertogenbosch: Arko Sports Media/W.J.H. Mulier Institute, 2005.

31. AusPlay NSW 2018. In: Australia S, (ed.). Clearinghouse for Sport, 2019.

32. Australian Sports Commission. AusPlay Participation Data for the Sport Sector. 2016.

33. Lin CSH, Chua CK and Yeo JH. Design of high performance badminton shuttlecocks: virtual and rapid prototyping approach. Virtual and Physical Prototyping 2013; 8: 165-171. DOI: 10.1080/17452759.2013.812738.

34. Lin CSH, Chua CK and Yeo JH. Designing a badminton shuttlecock; validation of virtual design by $3 \mathrm{D}$ printed thin-walled functional prototype. In: 1st International Conference on Progress in Additive Manufacturing (Pro-AM) 2014 (eds Kai CC, Yee YW, Jen TM, et al.), Singapore, 2014, pp.339-345.

35. Lin CSH, Chua CK and Yeo JH. Analysis and simulation of badminton shuttlecock flight through parameter identification of a slow-speed serve shot. Proceedings of the Institution of Mechanical Engineers, Part P: Journal of Sports Engineering and Technology 2015; 229: 213-221. Article. DOI: $10.1177 / 1754337114568825$. 
36. Salles AS and Gyi DE. The specification and evaluation of personalised footwear for additive manufacturing. In: Karwowski W and Salvendy G (eds) Advances in Human Factors, Ergonomics, and Safety in Manufacturing and Service Industries. Taylor and Francis, 2010, pp.355-366.

37. Salles AS and Gyi DE. The specification of personalised insoles using additive manufacturing. Work 2012; 41: 1771-1774. DOI: 10.3233/WOR-2012-0383-1771.

38. Salles AS and Gyi DE. Delivering personalised insoles to the high street using additive manufacturing. International Journal of Computer Integrated Manufacturing 2013; 26: 386-400. Article. DOI: 10.1080/0951192X.2012.717721.

39. Salles AS and Gyi DE. An evaluation of personalised insoles developed using additive manufacturing. Journal of Sports Sciences 2013; 31: 442-450. Article. DOI: 10.1080/02640414.2012.736629.

40. Salles AS, Gyi DE and Forrester SE. Evaluation of the short and medium term use of insoles for personalised footwear. Footwear Science 2011; 3: S144-S145. Article. DOI: 10.1080/19424280.2011.575816.

41. Toon D, Vinet A, Pain MTG, et al. A methodology to investigate the relationship between lowerlimb dynamics and shoe stiffness using custom-built footwear. Proceedings of the Institution of Mechanical Engineers, Part P: Journal of Sports Engineering and Technology 2011; 225: 32-37. DOI: $10.1177 / 1754337110396792$.

42. Vinet A and Caine M. Development of traction features in sprint spikes using SLS nylon sole units. In: 8th Conference of the International Sports Engineering Association (ISEA) Vienna, Austria, 2010, pp.2769-2774. Elsevier.

43. Vinet A and Caine M. Design, manufacture, and evaluation of traction features on sprint footwear using laser sintered nylon-12 sole units. Proceedings of the Institution of Mechanical Engineers, Part P: Journal of Sports Engineering and Technology 2011; 225: 259-264. DOI: $10.1177 / 1754337111408376$.

44. Brownlie L, Aihara Y, Carbo J, et al. The Use of Vortex Generators to Reduce the Aerodynamic Drag of Athletic Apparel. In: 11th conference of the International Sports Engineering Association (ISEA) 2016 Delft, The Netherlands, 2016, pp.20-25. Elsevier.

45. Joo J-Y and Kim Y-K. Effects of Customized 3D-printed Insoles on the Kinematics of Flat-footed Walking and Running. Korean Journal of Sport Biomechanics 2018; 28: 237-244. DOI: 10.5103/KJSB.2018.28.4.237.

46. Lee H, Ran-I E and Lee Y. Development of ergonomic leg guard for baseball catchers through 3D modeling and printing. Journal of Fashion Business 2016; 20: 17-29. DOI: 10.12940/jfb.2016.20.3.17.

47. Chowdhury H, Loganathan B, Wang Y, et al. A Study of Dimple Characteristics on Golf Ball Drag. In: 11th conference of the International Sports Engineering Association (ISEA) 2016 Delft, The Netherlands, 2016, pp.87-91. Elsevier.

48. Reiter M, Miron M and Major Z. Design and Simulation of a Polymeric 3D Printed Fall Arrest System for Climbing. In: 6th International Conference on Mechanics and Materials in Design (M2d2015) (eds Gomes JFS and Meguid SA), 2015, pp.563-564.

49. Kajtaz M, Witherow B, Leary M, et al. Design of a Personalised Faceguard for an Elite Cricketer. In: The 1st International Design Technology Conference, DESTECH2015 (eds Littlefair G, Gibson I, Usma C, et al.), Geelong, Australia, 2015, pp.199-205. Elsevier.

50. Nickels L. 3D printing the world's first metal bicycle frame. Metal Powder Report 2014; 69: 3840. Article. DOI: 10.1016/S0026-0657(14)70083-9.

51. Collins PK, Leen R and Gibson I. Industry case study: rapid prototype of mountain bike frame section. Virtual and Physical Prototyping 2016; 11: 295-303. Review. DOI: 10.1080/17452759.2016.1222563. 
52. McEwen I, Cooper DE, Warnett J, et al. Design \& Manufacture of a High-Performance Bicycle Crank by Additive Manufacturing. Applied Sciences 2018; 8. DOI: 10.3390/app8081360.

53. Cazon-Martin A, Iturrizaga-Campelo M, Matey-Munoz L, et al. Design and manufacturing of shin pads with multi-material additive manufactured features for football players: A comparison with commercial shin pads. Proceedings of the Institution of Mechanical Engineers Part P: Journal of Sports Engineering and Technology 2019; 233: 160-169. DOI: 10.1177/1754337118811266.

54. Harte D and Paterson A. The fastest field sport in the world: A case report on 3-dimensional printed hurling gloves to help prevent injury. Journal of Hand Therapy 2018; 31: 398-410. DOI: 10.1016/j.jht.2017.05.015.

55. Nessi A and Stankovic T. Topology, shape, and size optimization of additively manufactured lattice structures based on the superformula. In: ASME 2018 International Design Engineering Technical Conferences \& Computers and Information in Engineering Conference IDETC/CIE 2018 Quebec, Canada, 2018, ASME.

56. Vieira T, Botter A, Gastaldi L, et al. Textured insoles affect the plantar pressure distribution while elite rowers perform on an indoor rowing machine. PLoS One 2017; 12. DOI: 10.1371/journal.pone.0187202.

57. Gately RD, Beirne S, Latimer G, et al. Additive Manufacturing, Modeling and Performance Evaluation of 3D Printed Fins for Surfboards. MRS Advances 2017; 2: 913-920. DOI: 10.1557/adv.2017.107.

58. Depoorter B. Intellectual Property Infringements \& 3D Printing: Decentralized Piracy. Hastings Law Journal 2014; 65(6): 1483-503.59. Popescu D and Laptoiu D. Rapid prototyping for patientspecific surgical orthopaedics guides: A systematic literature review. Proceedings of the Institution of Mechanical Engineers, Part H: Journal of Engineering in Medicine 2016; 230: 495-515. DOI: 10.1177/0954411916636919.

60. Tack P, Victor J, Gemmel P, et al. 3D-printing techniques in a medical setting: a systematic literature review. BioMedical Engineering OnLine 2016; 15: 115. journal article. DOI: 10.1186/s12938-016-0236-4.

61. Martelli N, Serrano C, van den Brink H, et al. Advantages and disadvantages of 3-dimensional printing in surgery: A systematic review. Surgery 2016; 159: 1485-1500. DOI: 10.1016/j.surg.2015.12.017.

62. Bauermeister AJ, Zuriarrain A and Newman MI. Three-Dimensional Printing in Plastic and Reconstructive Surgery : A Systematic Review. Annals of Plastic Surgery 2016; 77: 569-576. DOI: $10.1097 /$ SAP.0000000000000671.

63. Asfia A, Novak JI, Mohammed MI, et al. A review of 3D printed patient specific immobilisation devices in radiotherapy. Physics and Imaging in Radiation Oncology 2020; 13: 30-35. DOI: 10.1016/j.phro.2020.03.003.

64. Benson CL, Triulzi G and Magee CL. Is There a Moore's Law for 3D Printing? 3D Printing and Additive Manufacturing 2018; 5: 53-62. DOI: 10.1089/3dp.2017.0041.

65. Gao W, Zhang Y, Ramanujan D, et al. The Status, Challenges, and Future of Additive Manufacturing in Engineering. Computer-Aided Design 2015; 69: 65-89. DOI: 10.1016/j.cad.2015.04.001. 